\section{Nondestructive Determination of Fruit Surface Area Using Archimedean Buoyancy}

\author{
Grecia Hurtado, Patrick Lüdeke, and Moritz Knoche \\ Institute of Horticultural Production Systems, Leibniz-University Hannover, \\ Herrenhäuser Straße 2, 30419 Hannover, Germany
}

Additional index words. Archimedes, buoyancy, water displacement, surface area, fruit surface area

\begin{abstract}
Estimates of fruit surface area are often required in physiological and technological studies. The objective was to establish a procedure to accurately quantify the fruit surface area based on Archimedean buoyancy measurements. The setup comprised a fixed, linear stepper motor mounted with its spindle vertical and aligned directly above the pan of an electronic balance. A fruit was clamped to the motor spindle and a beaker of water rested on the balance pan. When the motor was activated, the fruit was progressively immersed, stepwise, in the water. Each vertical displacement step increased the buoyant upthrust on the fruit, which was opposed by a corresponding increase in the downthrust on the balance. Pairs of the step displacement length $(\mathrm{mm})$ and corresponding buoyancy increment (g) values were recorded in an MS Excel (Microsoft, Redmond, WA) spreadsheet using Arduino components. Each displacement step immersed another "virtual slice" of the fruit in the water. From each pair of known displacement-buoyancy measurements, the volume $(\mathrm{mL})$ of that slice could be calculated with high precision based on the known density of the liquid $\left(\mathrm{g} \cdot \mathrm{mL}^{-1}\right)$. With the fruit orientated so that its morphological "long" axis was vertical, for most fruitcrop species, the slice can be assumed to have a circular cross-section. Hence, the slice can be analyzed geometrically as a truncated cone of known height $(\mathrm{mm})$ and known volume $(\mathrm{mL})$. Therefore, the surface area of its outer face is calculable. The surface area of the whole fruit was calculated as the cumulative total of the surface areas of all steps (virtual slices). The procedure was evaluated and calibrated using stainless-steel spheres in place of the fruit. However, the measured surface area was slightly greater than that calculated for a sphere. The calculated and measured areas did not differ by more than $1.7 \%$. The surface area determinations were highly reproducible $(\mathrm{CV}=\mathbf{0 . 9 5 \%})$. The magnitude of the displacement steps affected the variability of the surface area measurements. Increasing the step displacements decreased the measurement variability, but there were no significant effects on the surface area measurements of the surface tension of the liquid or of the wettability of the surface of the fruit or the stainless-steel subject. Using stainless-steel spheres (diameter, 5-60 mm) or rubber truncated cones (mean diameter, $8-45 \mathrm{~mm}$ ) revealed an excellent agreement between the measured and calculated surface areas. Using tomatoes, grapes, blueberries, and strawberries, the measured surface areas were in excellent agreement with those calculated from the fruit dimensions and appropriate geometrical assumptions. The results demonstrate that the surface areas of fruit with approximately circular cross-sections normal to their morphological axes can be determined with high accuracy and reproducibility using Archimedean buoyancy.
\end{abstract}

Received for publication 17 June 2020. Accepted for publication 3 Aug. 2020.

Published online 10 September 2020

This research was funded in part by grants from the Deutsche Forschungsgemeinschaft. The publication of this article was funded by the Open Access Fund of Leibniz Universität Hannover.

We thank Andreas Meyer and Ulrich Hering for building the displacement apparatus, Heike and Karl Walter Brüggenwirth and Bendix Meyer for the gift of fruit, and Alexander Lang and Andreas Winkler for helpful comments on an earlier version of this manuscript.

M.K. is the corresponding author. E-mail: moritz. knoche@obst.uni-hannover.de.

This is an open access article distributed under the CC BY-NC-ND license (https://creativecommons. org/licenses/by-nc-nd/4.0/).
Studies of fruit physiology and agricultural and food technology often require information regarding the fruit surface area. Typical examples are measurements of water uptake or transpiration (Beyer et al., 2005) or of gas exchange (e.g., $\mathrm{O}_{2}, \mathrm{CO}_{2}, \mathrm{C}_{2} \mathrm{H}_{4}$ ) through fruit surfaces (Cameron and Yang, 1982; Knee, 1991). These processes are often described using Fick's law of diffusion, for which knowledge of fruit surface area is a prerequisite for calculation of the permeability of the fruit skin (Cameron and Yang, 1982; Knee, 1991). Moreover, in studies of agrichemical spray application, the dose of the active ingredient retained per fruit depends (among other factors) on the fruit size or, more precisely, fruit surface area (Schlegel and Schönherr, 2002). In food technology, the estimation of the fruit surface area is central to calculations of fruit mass and heat transfer, which are important for shelf life determination, drying and freezing technologies, designing storage facilities, and applications of postharvest treatments (coatings, heat treatments, and designing minimally processed products) (Moreda et al., 2009).

Commonly, fruit surface areas are estimated by approximating the fruit shape using simple three-dimensional (3D) geometrical models. The surface area is then calculated from the major fruit dimensions. For closely spherical fruit, such as cherry tomatoes ( $\mathrm{So}$ lanum lycopersicum L.) or (less so) apples [Malus domestica (Suckow) Borkh.], the surface area may be calculated from the mean of the three orthogonal diameters of the fruit. This assumes that the fruit resembles a sphere or ellipsoid (Baten and Marshall, 1943; Clayton et al., 1995). The sphere and ellipsoid models may underestimate the actual surface area of fruit by as much as 15 to $18 \%$ for some apple cultivars. This is because their shape significantly departs from ellipsoidal (the stylar and stem cavities), thereby compromising the underlying assumption (Clayton et al., 1995). Similar 3D geometry approaches have been used to estimate surface areas of plum (Prunus domestica L. subsp. domestica) (Baten and Marshall, 1943), pear (Pyrus communis L.) (Baten and Marshall, 1943; Scharwies et al., 2014), and pepper (Capsicum annuum L. var. annuum) (Marcelis and Baan Hofman-Eijer, 1995). Moreover, different cultivars, even of the same species, differ markedly in shape. Additionally, the shapes of some common fruitcrops, such as strawberry (Fragaria xananassa Duchesne ex Rozier), are so far removed from being ellipsoidal that they require more sophisticated and complex $3 \mathrm{D}$ geometrical models with measurements of multiple dimensions, not just the three orthogonal ones.

Several alternative methods have been used for the direct determination of the fruit surface area. These include measuring the area of the fruit skin after peeling (destructive) or measuring the area of a film applied to the fruit as a coating that is subsequently peeled off (Clayton et al., 1995). Other methods that have been used to quantify the fruit surface area are image processing (Sabliov et al., 2002), structured light systems (Sakai and Yonekawa, 1992), atomic force microscopy (Hershko et al., 1998), and 3D scanners (Eifert et al., 2006). All these methods are laborious, and some require specific and/or costly equipment. To our knowledge, the Archimedes principle has not been used to quantify the fruit surface area. According to this principle, the buoyancy experienced by a body submerged in water equals the weight of the displaced water. Because the density of water is close to $1 \mathrm{~g} \cdot \mathrm{cm}^{-3}$, the weight of the displaced water (g) can be considered numerically equal to the volume $\left(\mathrm{cm}^{-3}\right)$ of the submerged body. The Archimedes principle has been used to quantify fruit volume (Baumann and Henze, 
1983; Clayton et al., 1995; Drazeta et al., 2004; Mohsenin, 1970; Sabliov et al., 2002).

The objective of our study was to investigate whether Archimedean buoyancy measurements could be used to quantify the surface areas of fruit with a circular crosssection (perpendicular to their morphological long axis). Setups for measuring fruit volume and fruit density are available in many horticultural laboratories and may be converted to surface area meters using the procedure described here.

\section{Materials and Methods}

Plant material. Blueberries (Vaccinium corymbosum L.), cherry tomatoes [Solanum lycopersicum L. var. cerasiforme (Alef.) Voss 'Roma' and 'Dulcita'], grapes (Vitis vinifera L. 'Sugraone Seedless'), and strawberries were purchased locally. The blueberry and strawberry cultivars were unknown. 'Pinova' apples (Malus $\times$ domestica Borkh.) were obtained from an experimental orchard of Leibniz University in Ruthe, Germany (lat. $52^{\circ} 14^{\prime} \mathrm{N}$, long. $9^{\circ} 49^{\prime} \mathrm{E}$ ). A stainless-steel wire (diameter, $2 \mathrm{~mm}$ ) was mounted on the stem end of a fruit using a fast-curing epoxy glue (UHU Plus Schnellfest; UHU, Bühl/Baden, Germany). The wire served as an extended fruit stalk to hold the fruit.

Equipment and calculations. The apparatus comprised a stepper motor (NEMA 23; Mysweety, Guangzhou, China) mounted on a rigid camera stand (Kaiser RLR; Kaiser Fototechnik, Buchen, Germany). The spindle of the stepper motor was equipped with a "sled" that had a female thread to engage with the male thread of the stepper motor spindle. This setup converted the rotational displacement of the stepper motor to linear displacement. A clamp mounted on the sled allowed the wire of the fruit to be attached. A balance (LA820; Sartorius, Göttingen, Germany) was placed immediately beneath the spindle, and this was linked to a laptop computer for direct data acquisition. Unless otherwise specified, a 100-mL glass beaker filled with deionized water was placed on the balance (Fig. 1). Activating the stepper motor allowed the fruit to be progressively lowered into the beaker in steps of defined displacement $(\mathrm{mm})$ and number. Any one step was followed by a 7-s delay period. Unless otherwise specified, the rate of submersion was 1.02 $\mathrm{mm} \cdot \mathrm{s}^{-1}$. As the fruit was progressively immersed, the buoyant upthrust on the fruit was recorded as the corresponding downthrust on the balance $(\mathrm{g})$, and this was converted to displaced water volume $(\mathrm{mL})$ by dividing by the known density of water $\left(\mathrm{g} \cdot \mathrm{mL}^{-1}\right)$.

A custom control unit was built using Arduino components (UNO R3; Arduino AG, Ivrea, Italy) to control the stepper motor, to read the balance, and to record the pairs of data values [balance $(\mathrm{g})$ and stepper motor $(\mathrm{mm})]$ in an MS Excel (Microsoft) spreadsheet. The spreadsheet calculated the increments in immersed fruit volume for each immersion step. Each step represented the

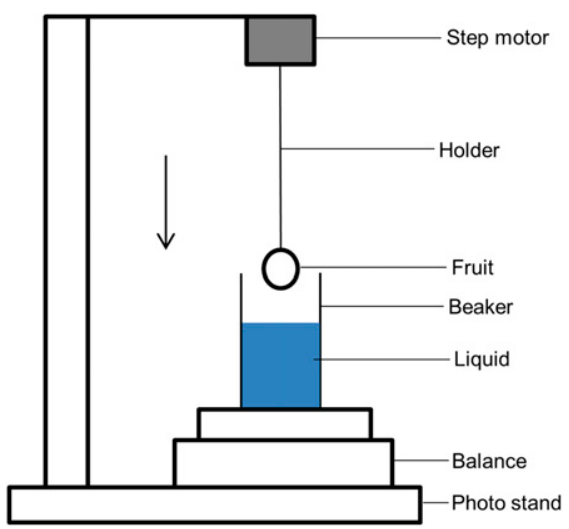

Fig. 1. Sketch of the setup for stepwise immersion of fruit in a beaker filled with deionized water and placed on an electronic balance.

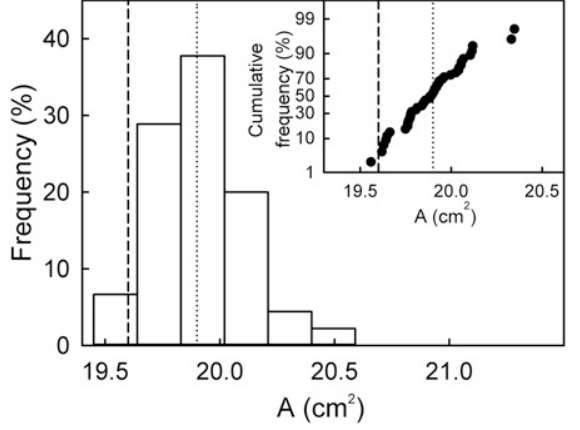

Fig. 3. Frequency distribution of the measured surface area $\left(\mathrm{A}_{\text {meas }}\right)\left(\mathrm{cm}^{2}\right)$ of a $25-\mathrm{mm}$ sphere (main graph). Inset: Normal probability plot of the measured surface area $(n=45)$. The dashed line represents the surface area calculated from sphere diameter and the dotted line represents the mean of the surface area of the stainless-steel sphere as measured by displacement.

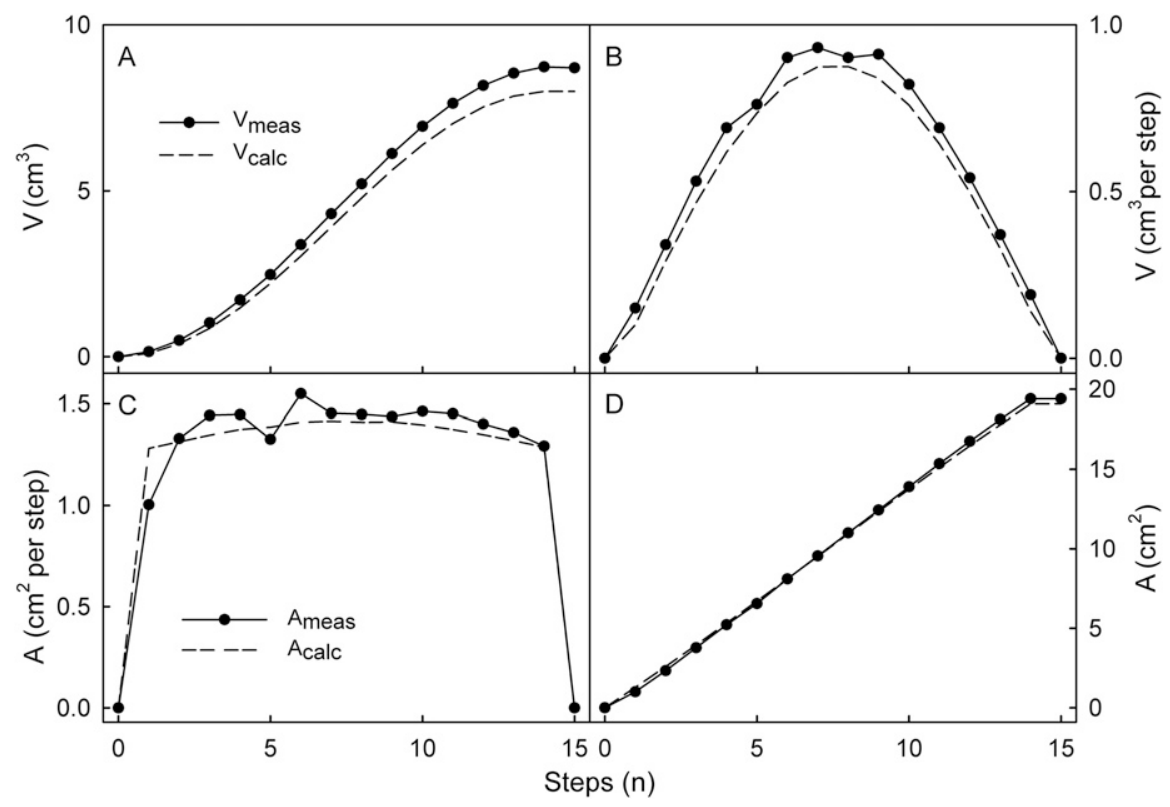

Fig. 2. (A) Cumulative volume $\left(\mathrm{V}_{\text {meas }}\right)\left(\mathrm{cm}^{3}\right)$ displaced by a stainless-steel sphere $(25 \mathrm{~mm}$ diameter $)$ as it is immersed stepwise. The dashed line represents the cumulative volume calculated from the sphere diameter $\left(\mathrm{V}_{\text {calc }}\right)$. (B) Volume per step measured and calculated. (C) Measured surface area $\left(\mathrm{A}_{\text {meas }}\right)$ and calculated surface area $\left(A_{\text {calc }}\right)$ per step. (D) Cumulative $A_{\text {meas }}$ and $A_{\text {calc }}$ as the sphere is immersed in water.

addition to the cumulative dataset of a new virtual slice of the fruit "cut" in a plane perpendicular to its morphological "long" axis (base to apex). Using the known volume $(\mathrm{mL})$ and thickness $(\mathrm{mm})$ of each virtual slice, its radius was calculated by assuming the fruit to have a circular cross-section and parallel sides (i.e., cylindrical). Necessary corrections were applied for the increase in water level in the beaker as the fruit was immersed (based on the known diameter of the beaker and the volume of the slice of fruit immersed). The surface area was calculated for each step as that of the outer surface of the truncated cone. Preliminary experiments established that there were no significant improvements in the calculation of the surface area when using the more complex model of a segment of a sphere in the calculation instead of that of a truncated cone (G. Hurtado, unpublished data). A summation of the incremental surface areas for all steps yielded the surface area of the whole fruit or sphere.

Experiments. The effect of step size (mm) on the surface area evaluation was investigated by immersing stainless-steel spheres (diameters of 15,25 , and $40 \mathrm{~mm}$ ) as described. The stainless-steel spheres served as artificial fruit. The step sizes were $0.4,0.8$, 1.6 , and $3.2 \mathrm{~mm}$. The rates of submersion ranged from $0.54 \mathrm{~mm} \cdot \mathrm{s}^{-1}$ at a step size of 

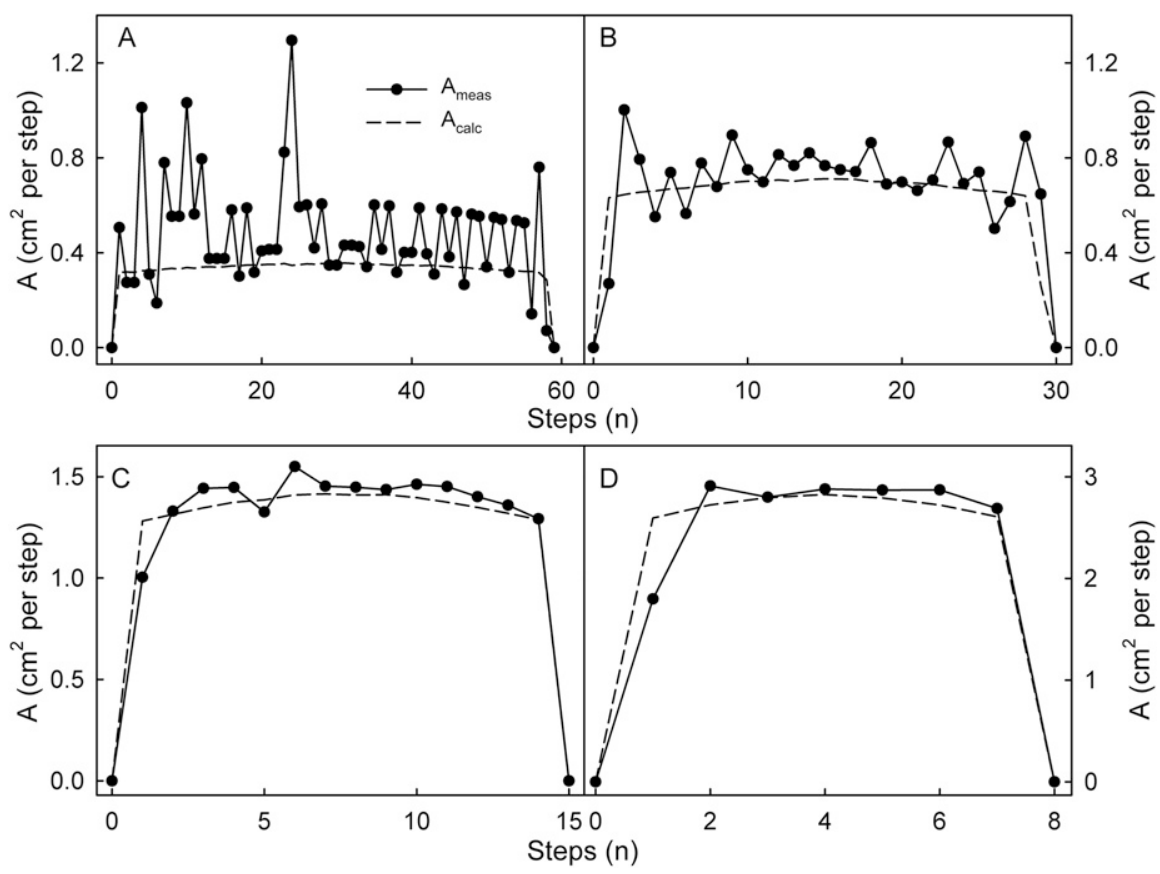

Fig. 4. Effect of step number during immersion of a stainless-steel sphere (diameter, $25 \mathrm{~mm}$ ) on the measured surface area per step $\left(\mathrm{A}_{\text {meas }}\right)$. The step number was varied by the varying step width. The number and width of steps were 59 and $0.4 \mathrm{~mm}(\mathbf{A}), 30$ and $0.8 \mathrm{~mm}(\mathbf{B}), 15$ and $1.6 \mathrm{~mm}(\mathbf{C})$, and 8 and $3.2 \mathrm{~mm}(\mathbf{D})$. The dashed line represents the surface area per step calculated from the sphere diameter and step width $\left(\mathrm{A}_{\text {calc }}\right)$.

$0.4 \mathrm{~mm}$ to $3.11 \mathrm{~mm} \cdot \mathrm{s}^{-1}$ at $3.2 \mathrm{~mm}$. The surface areas were calculated as described. The minimum number of replications was five.

The relationship between the beaker diameter and the size of the sphere was studied by immersing spheres with diameters of 15 , 25 , and $40 \mathrm{~mm}$ in $400-, 250-$, and $100-\mathrm{mL}$ glass beakers with diameters of 76,58 , and $44 \mathrm{~mm}$. The minimum number of replications was five.

The repeatability of the method was determined by repeating the surface area determinations of a stainless-steel sphere with a diameter of $25 \mathrm{~mm}$. The number of replications was 45.

The effect of surface tension on the surface area determinations was established using four liquids of a wide range of surface tensions: deionized water, sunflower oil, aqueous Tween $80(1.5 \% \mathrm{w} / \mathrm{v})$, and aqueous ethanol $(80 \% \mathrm{v} / \mathrm{v})$. Measurements were performed for three spheres (diameters of 15, 25, and $40 \mathrm{~mm}$ ). All calculations were performed using densities of the respective liquids. The effect of surface tension was also studied using truncated rubber cones with mean diameters of 8,19 , and $29 \mathrm{~mm}$. A minimum of five replications was used.

The effect of the wettability of the immersed surface on the surface area measurement was determined using a stainlesssteel ball with a diameter of $30 \mathrm{~mm}$ with either a roughened or a polished surface. Wettability differed significantly between the roughened and polished spheres. We also sprayed stainless-steel spheres with a water- repellent spray (AquaStop; Multicolor, served as the control. A minimum of five replications was used. The wettability of the spheres was characterized by measuring the contact angle according to Mack's equation (Mack, 1936). Briefly, the base width and height of a $5-\mu \mathrm{L}$ droplet of deionized water on the surface of the sphere were measured by digital analysis (cellSens Dimension 1.7.1; Olympus Soft Imaging Solutions $\mathrm{GmbH}$, Münster, Germany) on calibrated photographs. These photographs were obtained $30 \mathrm{~s}$ after placing the droplet on the surface. A preliminary time course established that this time interval was required to reach equilibrium. To minimize droplet evaporation, wet filter paper was placed on the sphere surface surrounding the droplet area. The minimum number of replications was 10.

Furthermore, the effect of wettability of the surface was tested using cherry tomato and grapes previously coated with water repellent spray (AquaStop; Multicolor). Untreated fruit surfaces served as controls. The minimum number of replications was five.

The procedure to quantify surface areas was calibrated by comparing measured and calculated surface areas of spheres and truncated cones. These served as model "fruit" with geometrical and simply defined shapes. A range of 14 stainless-steel spheres (diameter, 5-60 $\mathrm{mm}$ ) and a set of eight truncated rubber cones (mean diameter, $8-45 \mathrm{~mm}$ ) were investigated. The minimum number of replications was five. Osnabrück, Germany). Unsprayed spheres

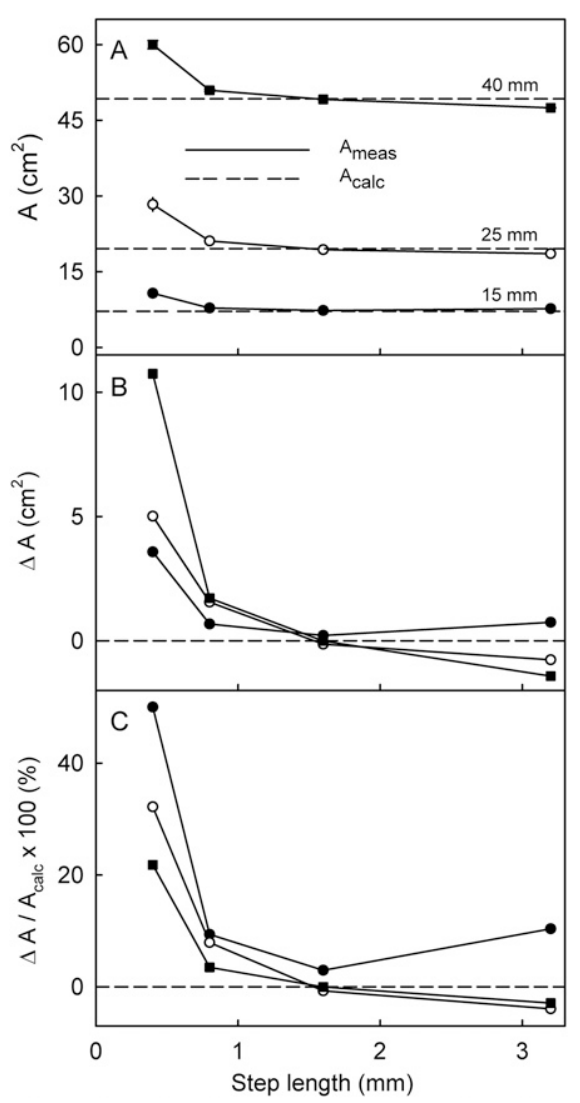

Fig. 5. (A) Effect of step length during immersion of stainless-steel spheres with diameters of 15 , 25 , and $40 \mathrm{~mm}$ on the measured surface area $\left(\mathrm{A}_{\text {meas }}\right)$, the absolute difference $(\Delta \mathrm{A})$ between $A_{\text {meas }}$ and the surface area calculated from sphere diameter $\left(\mathrm{A}_{\text {calc }}\right)(\mathbf{B})$, and the relative difference $\left(\Delta \mathrm{A} / \mathrm{A}_{\text {calc }} \times 100\right)$ between $\mathrm{A}_{\text {meas }}$ and $A_{\text {calc }}(\mathbf{C})$. The dashed line represents the surface area calculated from the respective sphere diameter $\mathrm{A}_{\text {calc. }}$. The step number varied according to the varying step length.

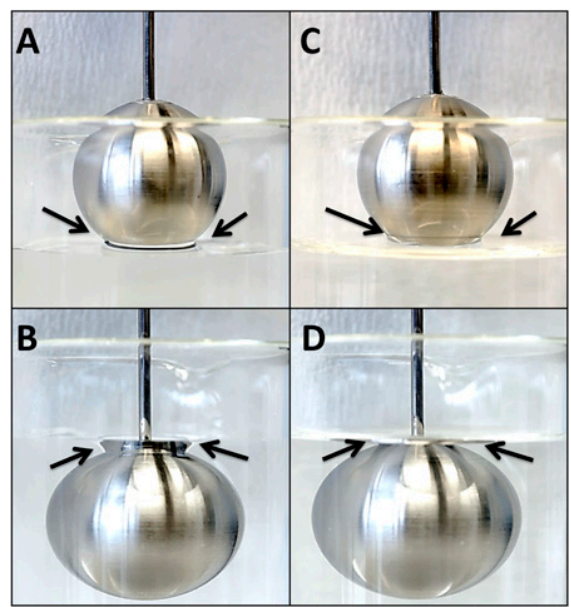

Fig. 6. Images of stainless-steel spheres during stepwise immersion in deionized water ( $\mathbf{A}$ and B) or ethanol (C and D). Arrows in (A) and (C) indicate the meniscus formed at the base of the sphere at the beginning of immersion in water (A) or ethanol (C). (B and D) Same as (A) and (C), but arrows indicate the top of the sphere at the end of the immersion in water $(\mathbf{B})$ or ethanol (D). 


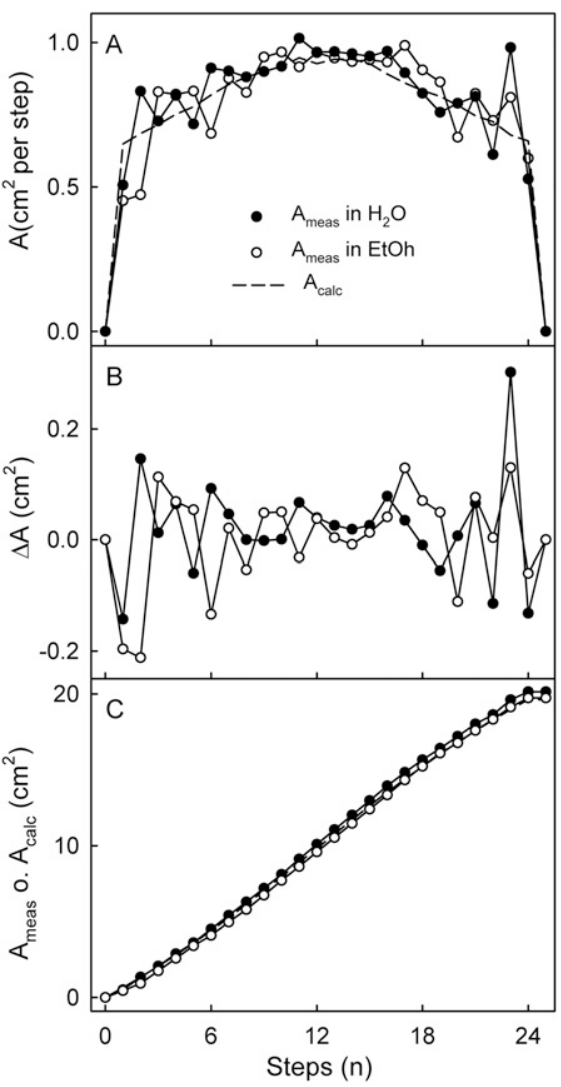

Fig. 7. Effects of stepwise immersion of a stainlesssteel sphere in deionized water $\left(\mathrm{H}_{2} \mathrm{O}\right)$ or ethanol $(\mathrm{EtOH})$ on the measured surface area per step $\left(\mathrm{A}_{\text {meas }}\right)(\mathbf{A})$, the difference in surface area between $A_{\text {meas }}$ and the surface area per step calculated from the sphere diameter $\left(\mathrm{A}_{\mathrm{calc}}\right)(\mathbf{B})$, and the cumulative measured and calculated surface areas $(\mathbf{C})$.

The applicability of the procedure to real fruit of varying sizes was established using cherry tomatoes ('Roma' and 'Dulcita'), grapes ('Sugraone Seedless'), blueberries, and strawberries. For the latter two, the cultivar names were unknown. The fruits were immersed and the surface area was determined as described. In addition, the surface areas were estimated using simple geometrical models. The 'Dulcita' tomatoes and blueberries were assumed to be perfect spheres. The 'Roma' tomatoes and grapes were assumed to be rotational prolate ellipsoids. For the strawberry, we used the model of a truncated cone capped by two oblate rotational semi-ellipsoids. The minimum number of individual fruit replications was 10 . Every fruit was measured five times.

The effects of concavities on surface area determinations were investigated using 'Pinova' apples. Five apples were selected to be of similar mass (mean mass, $114.6 \pm 1.6$ $\mathrm{g})$. The fruit stalk was removed. Using epoxy glue (UHU Plus Schnellfest; UHU), a stainless-steel wire (diameter, $2 \mathrm{~mm}$ ) was mounted as a virtual stalk: first on the stem end of a fruit, then on the calyx end, and, finally, on the cheek in the equatorial plane. For each stalk position, the fruit was sub- merged and its surface area was determined as described. Finally, all fruit including their stem and calyx cavities were peeled, the peel was flattened on a glass plate, and the peel surface area was determined by image analysis (cellSens Dimension 1.7.1; Olympus Soft Imaging Solutions $\mathrm{GmbH}$ ). The number of individual fruit replications was five.

Statistics. All experiments were conducted and analyzed using completely randomized designs. To compare the accuracy of the immersion measurement method to estimates based on the various geometrical models, the surface area was measured using Archimedes buoyancy and compared with the areas estimated based on calculations from the diameter of a simple sphere or the two diameters and height of a simple truncated cone. Subtracting the calculated surface areas from the measured surface areas yielded the absolute errors. The relative error (\%) was calculated by dividing the absolute error by the calculated surface area and multiplying by 100 .

Data were analyzed by analyses of variance and linear regression. Means were compared using Tukey's Studentized range test $(P \leq 0.05)$ using $\mathrm{R}$ (version 3.5.1; R Foundation for Statistical Computing, Vienna, Austria). Data are presented as means with SE.

\section{Results}

The volume of water displaced increased as a stainless-steel sphere was progressively immersed. Regarding the stainless-steel sphere, a comparison of the measured volume with the calculated volume revealed a small discrepancy that increased as the extent of immersion increased (Fig. 2A). As expected, the volume increment per step (calculated as the difference between two consecutive cumulative volume determinations) increased until the sphere was immersed to its equator; then, it decreased (Fig. 2B). The measured volume increment per step was slightly greater than the volume calculated using the diameter and step length. Similarly, the measured surface area increment per step was slightly greater than that calculated for a slice of a sphere with a thickness equal to the step length (Fig. 2C). The cumulative surface area obtained by summing the measured surface areas of the individual virtual slices of a sphere was in excellent agreement with the respective calculated cumulative surface area (Fig. 2D). The relative discrepancy between the two was $-0.75 \%$ compared with the area calculated from the sphere diameter.

Surface area measurements of stainlesssteel spheres with a standard diameter were highly reproducible, as indicated by a narrow and symmetrical frequency distribution (Fig. 3). The variability, as indexed by a $\mathrm{CV}$ of $0.95 \%$, was very low, indicating very high repeatability. The cumulative frequency distribution of measured surface areas was linear, suggesting a normal distribution. In general terms, the calculated and the mean measured surface areas did not differ by more than $1.7 \%$.

Step length had a significant effect on the surface area measurements (Fig. 4). Increas- ing the step length markedly decreased the variation in surface area for any one step. The areas per step measured using the shortest steps $(0.4 \mathrm{~mm})$ showed the greatest scatter and largest deviation from the calculated area (relative error $=35.8 \%$ ). For increasing step lengths, the variation decreased after a step length of $0.8 \mathrm{~mm}(\mathrm{CV}=0.72 \%)$. For the larger step lengths of 1.6 and $3.2 \mathrm{~mm}$, the scatter and deviation between the calculated and measured surface areas per step decreased markedly. For the latter, the $\mathrm{CV}$ were 0.41 and $0.14 \%$, respectively. These correspond to relative errors in the surface area determination of $-0.75 \%$ and $-3.8 \%$, respectively (Fig. 4).

The effect of step length did not depend on the sphere diameter (Fig. 5). As step length increased, the discrepancy between the measured and calculated areas decreased consistently for all sphere diameters (Fig. 5B). The relative errors were larger for the smaller spheres than for the intermediate and larger spheres (Fig. 5B and C).

The surface tension of the liquid used for the measurement had little effect on the volume displaced. When deionized water was used, a meniscus formed between the water surface and the sphere as a consequence of the high surface tension of the water:air meniscus. At the intersection of this air:water meniscus, with stainless steel, the contact angle will be $71^{\circ}$ (at the intersection between the three phases). The direction of the meniscus depended on position. It was concave for the "southern hemisphere" of the sphere but convex for the "northern" hemisphere (Fig. 6A and B).

When $80 \%(\mathrm{v} / \mathrm{v})$ aqueous ethanol, which has a lower surface tension $\left(23.8 \mathrm{mN} \cdot \mathrm{m}^{-1}\right)$ (Vazquez et al., 1995), was used the surface tension effects on the apparent sphere volume with progressive emersion were correspondingly reduced (Fig. 6C and D). A comparison of surface area measurements in water (high surface tension) and ethanol (low surface tension) did not reveal a consistent significant effect of surface tension despite the marked differences in meniscus formation (Fig. 7). The surface areas per step measured were essentially identical (Fig. 7A and B). The discrepancies between measured and calculated surface areas were negligibly small and never exceeded $30 \mathrm{~mm}^{2}$ (Fig. 7B). In cumulative terms, the calculated and measured surface areas did not differ by more than $2.5 \%$ (Fig. 7C).

There were no consistent effects of surface tension when surface areas of smaller (diameter, $15 \mathrm{~mm}$ ) or larger (diameter, $40 \mathrm{~mm}$ ) spheres were measured. The relative error increased to $7.2 \%$ with smaller spheres but remained at $\approx 1.3 \%$ for all larger spheres. Regression lines calculated for the relationships between calculated and measured surface areas had highly significant $r^{2}$ and slopes very close to 1.0 , regardless of the surface tension of the liquid used (Table 1).

Wettability of the surfaces of roughened and polished spheres with and without treatment with a water repellent spray differed 
Table 1. Parameters of regression equations for the relationship between the measured surface area $\left(\mathrm{A}_{\text {meas }}\right)$ and the surface area calculated from the diameter of a stainless-steel sphere $\left(\mathrm{A}_{\text {calc }}\right)$. The regression model was: $\mathrm{A}_{\text {meas }}\left(\mathrm{cm}^{2}\right)=\mathrm{b} \times \mathrm{A}_{\text {calc }}\left(\mathrm{cm}^{2}\right)$.

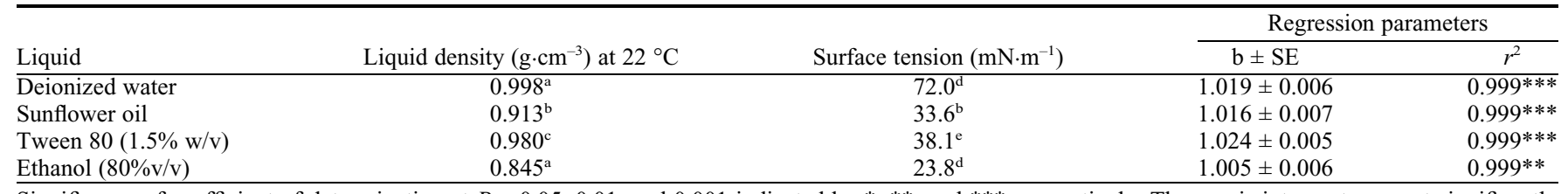

Significance of coefficient of determination at $P<0.05,0.01$, and 0.001 indicated by $*, * *$, and ***, respectively. The y-axis intercept was not significantly different from the origin. Hence, regression lines were forced through the origin. Density and surface tension values were taken from ${ }^{a}$ Stratton (1916), ${ }^{b}$ Esteban et al. (2012), ${ }^{\mathrm{c}}$ Farhadieh (1973), ${ }^{\mathrm{d}}$ Vazquez et al. (1995), and ${ }^{\mathrm{e}}$ Kothekar et al. (2007)

Table 2. Effect of wettability of stainless-steel spheres on the measured surface area $\left(\mathrm{A}_{\text {meas }}\right)$ and the surface area calculated from sphere diameter $\left(\mathrm{A}_{\mathrm{cal}}\right)$. The $\Delta \mathrm{A}$ is calculated as the difference between the $\mathrm{A}_{\text {meas }}$ and $\mathrm{A}_{\text {calc. }}$. Data represent mean $\pm \mathrm{SE}$.

\begin{tabular}{cccccc}
\hline Surface & Coated & Contact angle $\left(^{\circ}\right)$ & $\mathrm{A}_{\text {calc }}\left(\mathrm{cm}^{2}\right)$ & $\mathrm{A}_{\text {meas }}\left(\mathrm{cm}^{2}\right)$ & $29.8 \pm 0.4^{\mathrm{Ns}}$ \\
\hline Blunt & - & $96.0 \pm 1.6 \mathrm{a}^{*}$ & $28.1 \pm 0.0$ & $29.5 \pm 0.2$ & $1.6^{\mathrm{NS}}$ \\
& + & $119.7 \pm 0.7 \mathrm{~b}$ & $28.1 \pm 0.0$ & $29.8 \pm 0.1$ & 1.4 \\
Polished & - & $90.4 \pm 1.8 \mathrm{c}$ & $27.6 \pm 0.0$ & 2.2 \\
& + & $119.4 \pm 0.8 \mathrm{~b}$ & $27.6 \pm 0.0$ & $29.1 \pm 0.5$ \\
\hline
\end{tabular}

*Mean separation within columns by Tukey's Studentized range test at $P \leq 0.05$.

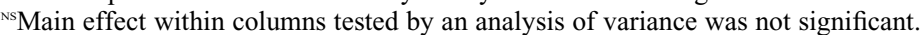

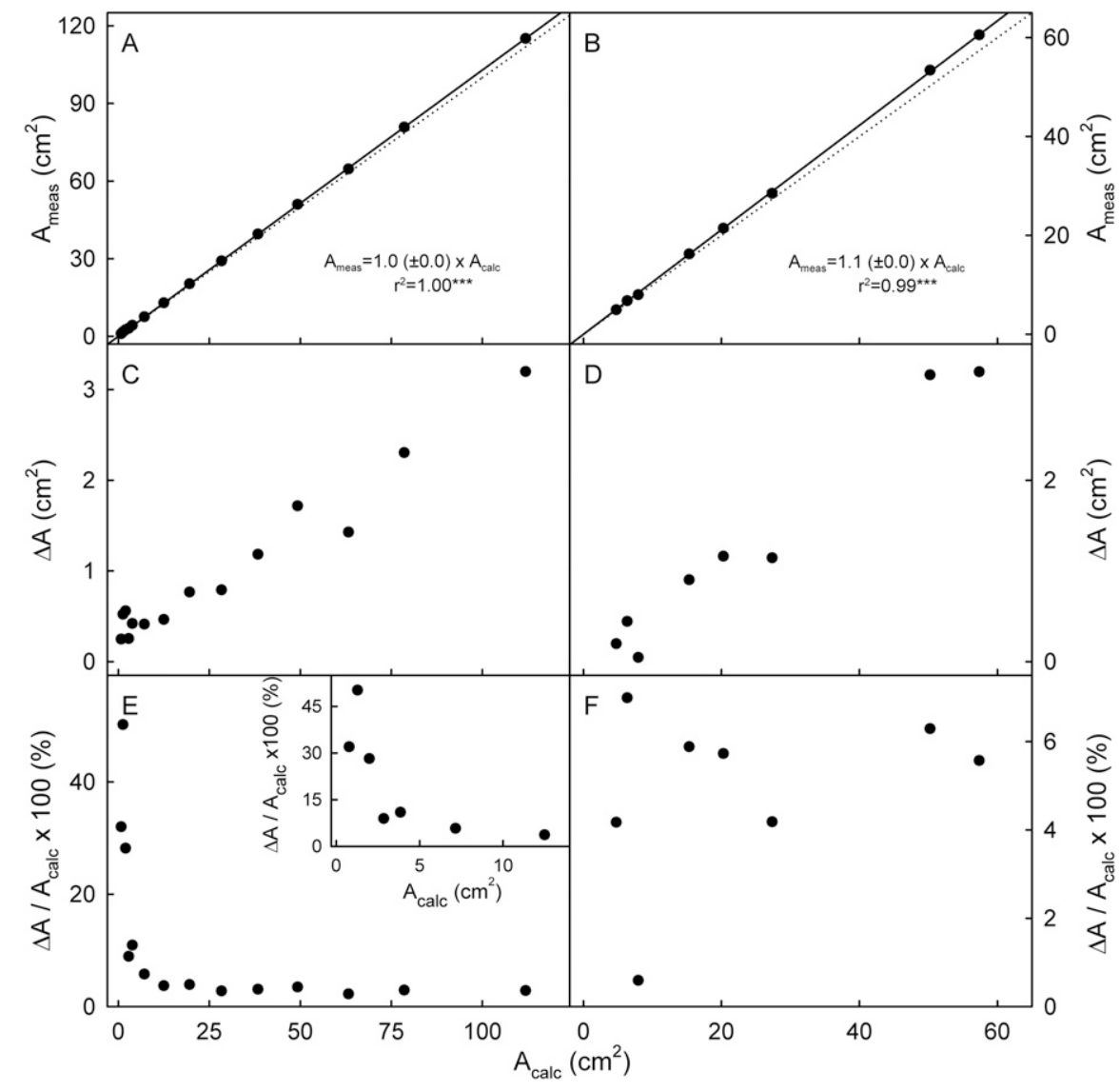

Fig. 8. Relationship between the calculated surface area of spheres $\left(\mathrm{A}_{\text {calc }}\right)(\mathbf{A})$ and truncated rubber cones (B) of varying dimensions and the measured surface area $\left(\mathrm{A}_{\text {meas }}\right)$. Relationship between $\mathrm{A}_{\text {calc }}$ and the absolute difference $(\Delta \mathrm{A})$ between $\mathrm{A}_{\text {meas }}$ and $\mathrm{A}_{\text {calc }}$ for spheres $(\mathbf{C})$ and truncated cones $(\mathbf{D})$ Relationship between $A_{\text {calc }}$ and the difference $\left(\Delta A / A_{\text {calc }} \times 100\right)$ between $A_{\text {meas }}$ and $A_{\text {calc }}$ for spheres $(\mathbf{E})$ and truncated cones $(\mathbf{F})$. Significance of coefficients or determination $\left(r^{2}\right)$ at $P \leq 0.05,0.01$, and 0.001 indicated by $*, * *$, and ${ }^{* *}$. Dashed line indicates a slope of 1 .

significantly (Table 2). The roughened spheres were more difficult to wet than the polished spheres. Applying a water repellent spray rendered surfaces of both roughened and polished spheres that were more difficult to wet. Despite the different wettability, there was no significant effect on the surface area measurement (Table 2). Measured surface areas of spheres remained the same before and after treatment with a water repellent.
The absolute error was always positive and not significantly different with and without water repellent. The relative errors in surface area were always $<5 \%$. Also, there were no differences in measured surface areas when tomatoes and grapes were treated with water repellent spray (data not shown).

We calibrated the method using standard geometrical objects of different sizes. This revealed excellent agreement between the measured surface area from displacement experiments and the calculated surface area based on their dimensions. The slopes were very close to 1.0 (Fig. $8 \mathrm{~A}$ and $\mathrm{B}$ ). The absolute error increased as the size of the spheres and truncated cones increased (Fig. 8C and D). For the spheres, the relative error decreased as the diameter increased (Fig. 8E). For the truncated cones, size had no consistent effect on the relative error of surface area determinations.

The displacement method was applied to fruits of a range of different species. Excellent linear relationships were obtained between the surface areas measured by displacement and the surface areas calculated using fruit dimensions and simple geometrical models. Generally, the slopes were very close to 1 , and all $r^{2}$ were highly significant (Fig. 9). Only with 'Roma' tomatoes was the slope 1.19, indicating a larger discrepancy $(+19 \%)$ between the measured and calculated surface areas. This discrepancy was probably more likely the result of oversimplification of the geometrical approximations (spherical fruit or rotational ellipsoids) than a result of the displacement method.

When measurements of apples were performed and the virtual stalk was mounted in the stem cavity, air collected in the (opposing) calyx cavity during submersion. Similarly, when the virtual stalk was mounted in the calyx cavity, air accumulated in the (opposing) stem cavity. However, when the virtual stalk was mounted on the cheek in the equatorial plane, no air was entrapped in the calyx or stem cavities. The surface areas 


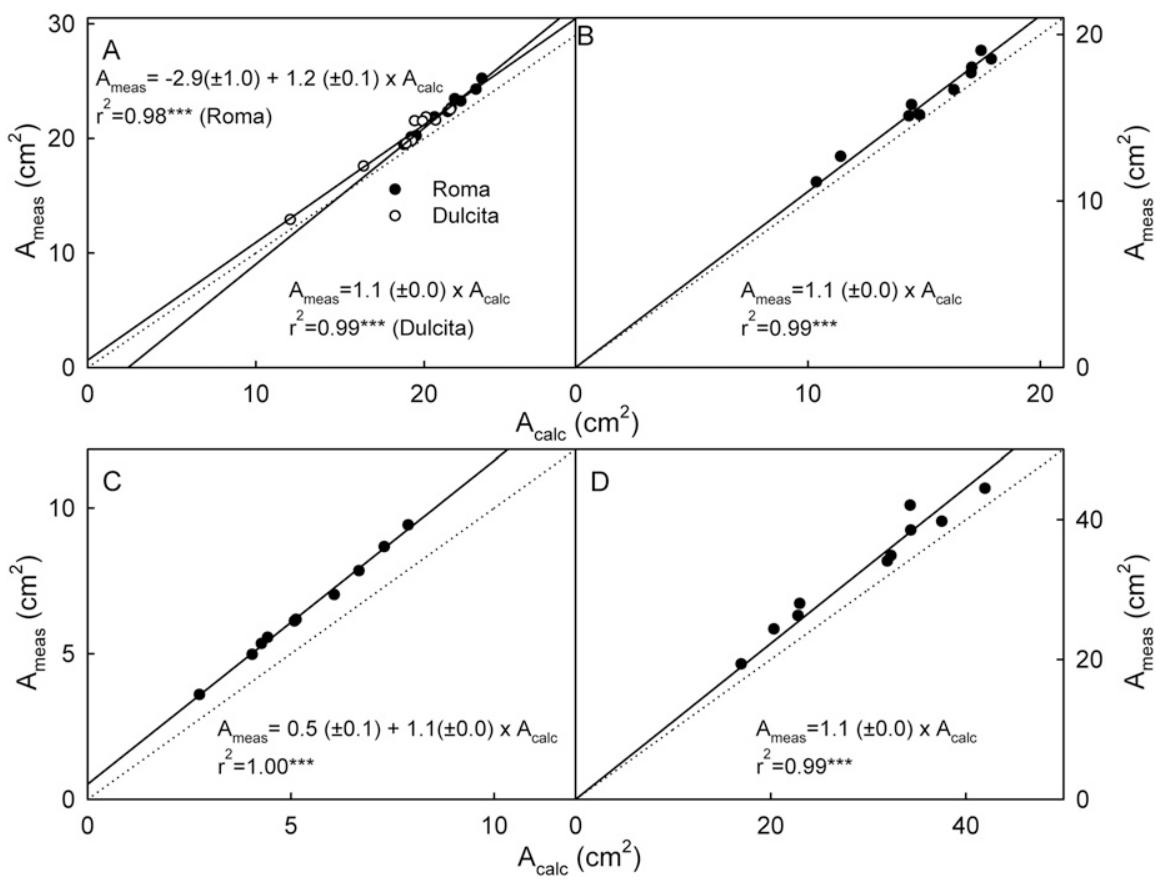

Fig. 9. Relationship between the calculated surface area $\left(\mathrm{A}_{\text {calc }}\right)$ and the measured surface area $\left(\mathrm{A}_{\text {meas }}\right)$ of (A) cherry tomatoes, (B) grapes, (C) blueberries, and (D) strawberries. Parameters of regression equations for the regression: $A_{\text {meas }}\left(\mathrm{cm}^{2}\right)=\mathrm{a}+\mathrm{b} \times \mathrm{A}_{\text {calc }}\left(\mathrm{cm}^{2}\right)$. Significance of coefficients or determination $\left(r^{2}\right)$ at $P \leq 0.05,0.01$, and 0.001 indicated by *,**, and ***. Dashed line indicates a slope of 1 .

Table 3. Effect of the stem and calyx cavities on the measured surface area $\left(\mathrm{A}_{\text {meas }}\right)$ of apple fruit. The effects of the two cavities were investigated by mounting a stainless-steel wire as a virtual stalk in the stem cavity, in the calyx cavity, or on the cheek in the equatorial plane. For each virtual stalk position, the fruit was submerged and its surface area was determined by displacement. The true surface area of the peel was later determined by an image analysis $\left(\mathrm{A}_{\text {calc }}\right)$ to serve as a comparison. The values of $\Delta \mathrm{A}$ were calculated as the differences between $A_{\text {meas }}$ and $A_{\text {calc }}$. Data represent means $\pm \mathrm{SE}$.

\begin{tabular}{lcccc}
\hline $\begin{array}{l}\text { Virtual stalk } \\
\text { position }\end{array}$ & $\begin{array}{c}\text { Orientation of } \\
\text { the stem cavity }\end{array}$ & $\mathrm{A}_{\text {meas }}\left(\mathrm{cm}^{2}\right)$ & $\Delta \mathrm{A}\left(\mathrm{cm}^{2}\right)$ & $\frac{\Delta \mathrm{A}}{\mathrm{A}_{\text {calc }}} \times 100(\%)$ \\
\hline Stem cavity & Upward & $125.3 \pm 1.8 \mathrm{a}^{\mathrm{z}}$ & $-5.6 \pm 1.7 \mathrm{a}$ & -4.3 \\
Calyx cavity & Downward & $128.0 \pm 2.1 \mathrm{a}$ & $-2.9 \pm 1.0 \mathrm{a}$ & -2.2 \\
Cheek & Sideways & $129.4 \pm 1.7 \mathrm{a}$ & $-1.6 \pm 1.8 \mathrm{a}$ & -1.2 \\
\hline
\end{tabular}

${ }^{\mathrm{z}}$ Means within columns do not differ according to the analysis of variance, $P \leq 0.05$.

determined among the three fruit orientations did not differ significantly from one another or from that determined from the peeled skin (Table 3). However, the deviations from the areas measured from the peeled skin were smallest when the virtual stalk was mounted on the cheek.

\section{Discussion}

Our results show that surface areas of fruit that have a circular cross-section in the plane lying normal to their morphological longitudinal axes can be determined with high reproducibility and accuracy by the displacement method.

The wettability of the fruit surface and the surface tension of the immersion liquid had only very minor effects on the surface area determinations. Only when working with very small fruit were the relative errors of surface area determination significant. For example, for steel spheres (diameter $\geq 15 \mathrm{~mm}$ ) and truncated cones, the average relative errors were $3.3 \%$ and always less procedure. Air bubbles will collect in these cavities during submersion, leading to an overestimation of fruit volume. Depending on the geometry of the cavity, this could result in an underestimation of the true surface areas. Therefore, a possible adaptation might be to fill these cavities with a silicone sealant (to render the fruit convex or plane only, i.e., no concavities). Then, both castings could be removed to determine the surface areas. Following the appropriate corrections, a true surface area of the fruit could be obtained. Alternatively, a virtual stalk mounted on the cheek in the equatorial plane will avoid retention of air in either cavity. However, this procedure may introduce a new error if the fruit was not symmetrical along the rotational axis. These errors were small, at least for apples. The procedure described herein is also useful to derive empirical equations that predict fruit surface area from readily obtainable fruit properties such as mass, volume, diameter, or height. Such models will be helpful in all research requiring estimates of the surface area.

\section{Literature Cited}

Baten, W.D. and R.E. Marshall. 1943. Some methods for approximate prediction of surface area of fruits. J. Agr. Res. 66:357-373.

Baumann, H. and J. Henze. 1983. Intercellular space volume of fruit. Acta Hort. 138:107111

Beyer, M., S. Lau, and M. Knoche. 2005. Studies on water transport through the sweet cherry fruit surface: IX. Comparing permeability in water uptake and transpiration. Planta 220:474-485.

Cameron, A. and S. Yang. 1982. A simple method for the determination of resistance to gas diffusion in plant organs. Plant Physiol. 70:21-23.

Clayton, M., N. Amos, N. Banks, and R. Morton. 1995. Estimation of apple fruit surface area. $\mathrm{N}$. Z. J. Crop Hort. Sci. 23:345-349.

Drazeta, L., A. Lang, A.J. Hall, R.K. Volz, and P.E. Jameson. 2004. Air volume measurement of 'Braeburn' apple fruit. J. Expt. Bot. 55:10611069.

Farhadieh, B. 1973. Determination of CMC and partial specific volume of polysorbates 20,60 , and 80 from densities of their aqueous solutions. J. Pharm. Sci. 62:1685-1688.

Eifert, J., G. Sanglay, D.-J. Lee, S. Sumner, and M. Pierson. 2006. Prediction of raw produce surface area from weight measurement. J. Food Eng. 74:552-556.

Esteban, B., J.-R. Riba, G. Baquero, R. Puig, and A. Rius. 2012. Characterization of the surface tension of vegetable oils to be used as fuel in diesel engines. Fuel 102:231-238.

Hershko, V., D. Weisman, and A. Nussinovitch. 1998. Method for studying surface topography and roughness of onion and garlic skins for coating purposes. J. Food Sci. 63:317-321.

Knee, M. 1991. Rapid measurement of diffusion of gas through the skin of apple fruits. HortScience 26:885-887.

Kothekar, S., A. Ware, J. Waghmare, and S. Momin. 2007. Comparative analysis of the properties of Tween 20, Tween 60, Tween 80, Arlacel 60, and Arlacel 80. J. Dispers. Sci. Technol. 28:477-484.

Mack, G. 1936. The determination of contact angles from measurements of the dimensions of small bubbles and drops. I. The spheroidal 
segment method for acute angles. J. Phys. Chem. 40:159-167.

Marcelis, L.F.M. and L.R. Baan Hofman-Eijer. 1995. Growth analysis of sweet pepper fruits (Capsicum annuum L.). Acta Hort. 412:470 478.

Mohsenin, N.N. 1970. Physical properties of plant and animal materials. Gordon and Breach Science Publishers, New York.

Moreda, G., J. Ortiz-Cañavate, F. García-Ramos, and M. Ruiz-Altisent. 2009. Non-destructive technol- ogies for fruit and vegetable size determination-a review. J. Food Eng. 92:119-136.

Sabliov, C., D. Boldor, K. Keener, and B. Farkas. 2002. Image processing method to determine surface area and volume of axi-symmetric agricultural products. Intl. J. Food Prop. 5:641-653

Sakai, N. and S. Yonekawa. 1992. Three-dimensional image analysis of the shape of soybean seed. J. Food Eng. 15:221-234.

Scharwies, J.D., E. Grimm, and M. Knoche. 2014 Russeting and relative growth rate are posi- tively related in 'Conference' and 'Condo' pear. HortScience 49:746-749.

Schlegel, T. and J. Schönherr. 2002. Stage of development affects penetration of calcium chloride into apple fruits. J. Plant Nutr. Soil Sci. 165:738-745.

Stratton, S.W. 1916. Standard density and volumetric tables. Circ. Bur. Stnd. 19:10-12.

Vazquez, G., E. Alvarez, and J. Navaza. 1995. Surface tension of alcohol water+ water from 20 to $50{ }^{\circ} \mathrm{C}$. J. Chem. Eng. Data 40:611-614. 